\title{
IRONIAS DEL FEDERALISMO EN LA PROVINCIA DEL SOCORRO, 1810-1870
}

\author{
Richard Stoller \\ The Pennsylvania State University
}

\section{IRONÍAS DEL FEDERALISMO}

La cuestión centralista/federalista ocupa un sitio inestable dentro de la historiografía reciente sobre el siglo XIX. latinoamericano. La organización estatal va se perfila como un tema instrumentalizado en vez de primordial, frente a temas como el régimen económico, cuyos "intereses" (por múltiples y confusos que sean) presumiblemente existen y son analizables; o quizás la cuestión religiosa, que se presta a cierta "irreductibilidad" para quienes no sean marxistas vulgarísimos.' En la mayoría de los estudios recientes sobre la pugna liberal/conservadora (usualmente con énfasis en el lado liberal), se nota la relativa ausencia del tema centralista/federalista, siempre con algunas excepciones notables. ${ }^{2}$ Esto no debe sorprender: ver al tema como la mera instrumentalización oportunista de otras preocupaciones, de otros intereses, conduce fácilmente a la conclusión de que no merece ser estudiado "en sí." Siempre existirá un motivo obvio para estudiarlo como discurso: para los que tienen esa inclinación, el mero hecho de haberse empleado los términos en su época representa prue-

1 Por ejemplo, Frank Safford, "Politics, Ideology and Society," Leslie Bethell (ed.), Cambridge History of Latin America, Spanisb America After Independence, c.1820-c.1870, New York, Cambridge University Press, 1987, pp. 84-85; David Bushnell, The Making of Modern Colombia, Berkeley, University of California Press, 1993, pp. 91-92.

2 Especialmente sobre México, como Peter Guardino, Peasants, Politics, and tbe Formation of Mexico's National State: Guerrero, 1800-1857, Stanford, Stanford University Press, 1996. 
ba adecuada de su importancia. ${ }^{3}$ Pero, para quienes desean "ir al grano" en forma más convencional, ¿qué hacer? Este artículo se propone volver al tema con el fin de trasladarlo desde las polaridades abstractas (y supuesta irreducibilidad filosófica) de la historiografía tradicional, a un enfoque más dialéctico, multinivelado, y en fin, complejo.

Pero no hay nada más común que encontrar que la anunciada complejidad histórica resulta ser una mera confusión, llena de curiosidades empíricas pero sin ningún peso acumulativo. Una regla medianamente útil para distinguir entre complejidad y confusión es la existencia, en el primer caso, de ironías, en el sentido de curiosidades estructuradas. Con este punto de partida, he aquí tres ironías notables del tema centralista/federalista en la América Latina decimonónica, con relevancia especial para Colombia:

1) El federalismo, que suele definirse (algo ligeramente) como el aumento del poder local en detrimento del poder central, usualmente fue el enemigo mortal del poder verdaderamente local -del distrito-, o después de 1829, del municipio, en el léxico institucional colombiano. Sería más preciso decir que el federalismo significaba el poder estatal regional, armado con una posibilidad logística (fruto de la relativa cercanía) de debilitar al poder local que el raquíticamente centralizado estado colonial (y post-colonial) jamás se pudo imaginar, y fortalecido a veces por una soberbia ideológica. Hay, pues, tres niveles enfrentados, introduciendo (por ejemplo) la posibilidad de que el centralismo pueda representar la mejor garantía para preservar cierta autonomía local, como pasaré a exponer más abajo. Además, en la Colombia decimonónica existió un cuarto nivel, el del cantón, para turbar un poco más la situación.

2) Los profesores del tema saben que el esquema "Liberal = Federalista / Conservador - Centralista" suministrada al estudiantado no funciona en todos los casos históricos latinoamericanos, pero lo curioso es que el esquema no tiene coherencia alguna. En estas sociedades poco o nada liberales, los liberales quieren el cambio, para tal fin deberían tener necesidad de un estado fuerte, lo más centralizado posible. (Es cierto que los liberales del medio siglo granadino dijeron creer que los cambios deseados fluirían más o menos espontáneamente de la ciudadanía sin más intervención estatal que la conscientización, pero después de la guerra del 60 esta idea se descarta como atolondrada y suicida. En cambio, los- conser-

3 Buenos ejemplos de la nueva ola de análisis de los discursos en estudios sobre la época incluyen a Francisco Gutiérrez Sanín, Curso y discurso del movimiento plebeyo, 1849/1854, IEPRI/E1 Ancora, 1995, y HansJoachim Kónig, En el camino hacia la nación, Bogotá, Banco de la República, 1994. 
vadores, en la medida en que desean mantener una especie de orden neocolonial, no deberían requerir un estado centralizado y fuerte (en circunstancias normales), sino una infinidad de situaciones locales de jerarquía tradicional, cuya mejor garantía de vigencia permanente parecería encontrarse en la devolución del poder hacia los estratos inferiores- con las salvedades señaladas en el numeral anterior. ${ }^{4}$

3) La tercera ironía es la más contundente de todas, pero quizás no tan misteriosa como las dos anteriores: ¿De dónde vienen los centralistas de provincia? En el caso colombiano no se trata de una Argentina, de un Perú, o siquiera de un México, donde el peso específico de la ciudad capital (más su región circundante) suministra en sí una base importante para el centralismo, en cuanto a recursos políticos, militares, intelectuales, y fiscales. Se trata de un país cuya ciudad capital goza de una situación geográfica poco envidiable, con una evolución demográfica y económica muy mediocre hasta finales del siglo- en fin, si el centralismo colombiano dependiera únicamente de Bogotá (más la Sabana) como soporte, la pugna se habría decidido por el lado federalista sin más. Obviamente hubo muchos centralistas fuera de Bogotá en cada momento, y no es factible que todos lo fueran porque tuvieran esperanzas de venir a la capital a mandar.

\section{EL CASO COLOMBIANO}

Estas observaciones someras nos permiten pensar en una nueva historia de la estructuración del estado colombiano. Los análisis usualmente han puesto énfasis en la condición de ser Colombia un "país de regiones," un "archipiélago" según Antonio García, ${ }^{6}$ esta idea conduce fácilmente a la hipótesis del federalismo como expresión natural de esta condición. No obstante su merecida reputación como el país latinoamericano que produjo el federalismo más exagerado en las Constituciones de 1858 y 1863, seguido por el más sofocante centralismo en la de 1886 (lo cual demuestra el grado de aversión que ejerció el extremo federalismo entre sus opositores), Colombia resulta ser territorio

4 Nótese que los "Neo-Borbones," término inventado por Frank Safford para caracterizar a los tibios y autoritarios reformistas — progresistas y ministeriales— de la época 1819-1849, encontraron la más tenaz resistencia a sus proyectos (cj., sobre la educación superior) a nivel local/regional. Frank Safford, El ideal de lo práctico, Bogotá, Universidad Nacional, 1989.

5 Una de las pocas obras que se interesa por el "centralismo en provincia" es la tesis doctoral de Ariel de la Fuente, Caudillo and Gaucho Politics in the Argentina State Formation Process, La Rioja, 18531870, SUNY-Stony Brook, Ph.D. tesis, 1995.

6 Antonio García, ¿Adonde va Colombia? De la república señorial a la crisis del capitalismo dependiente, Bogotá, Ed. Tiempo Americano, 1981, pp. 7-57. 
sorprendentemente ingrato para un análisis del federalismo como fruto de una "pugna de regiones," o de una pugna de fuertes regiones contra el Centro. ' Para el siglo XIX, la única región de Colombia donde hay una tolerable unidad entre jurisdicción territorial (en el largo plazo), identidad colectiva (ampliamente difundida, social y espacialmente), y agenda económica-fiscal, es Antioquia, como queda demostrado en el trabajo de María Teresa Uribe y Jesús Alvarez. ${ }^{8}$ Otras regiones no cumplieron con el primer requisito (ej. el nororiente, la Costa Atlántica), o el segundo (ej. el Cauca) y casi todas las regiones con la excepción de Antioquia sufrían severas limitaciones en la expresión de una política económica regional, o por exceso de diversidad interna (otra vez el Cauca), o por que su característica definidora fue indivisible y por eso, constantemente disputada (véase la Costa, una "región portuaria" con varias ciudades en pelea para ser el puerto principal), o porque eran tan homogéneas en su cuasiautarquía que ninguna subregión tuvo urgente necesidad de vincularse con las demás (y aquí propongo al Socorro como caso principal). ${ }^{9}$ Sean las que fueran las razones, las regiones colombianas generalmente carecieron de una proyección a nivel nacional como tales, o para promover una agenda legislativa/presupuestal, o para tumbar al estado central para adelantar esa agenda hipotética "en casa."

Este panorama nos ofrece un federalismo algo moroso y cansado, analizado "en grande": un federalismo producto de la manifiesta incapacidad del estado central para gobernar, y mucho menos idear y llevar a cabo un proyecto (palabra predilecta de los historiadores de hoy) de alguna envergadura. Bajo esta lupa, hasta la Guerra de los Supremos (1839-42), aquella "rebelión federalista" por excelencia, aparece como una "fuga de cárcel" oportunista, por caudi-

7 Aquí se destaca como valiosa excepción la obra de James William Park, Rafael Núñez and the Politi.cs of Colombian Regionalism, 1863-1885, Bacon Rouge, LSU Press, 1986; es de observar que su esquema funciona con base en los conflictos sobre proyectos leoninos de obras públicas (especialmente el Ferrocarril del Norte), que no arrancan sino después de la victoria liberal de 1861, y difícilmente funcionaría para la época anterior. También hay que destacar que la obra de Park es una narrativa multihilvanada, en el mejor estilo anglosajón, y no pretende "encuadrar" toda la historia política de la era dentro de la perspectiva regionalista.

8 Véase María Teresa Uribe de Hincapié y Jesús Alvarez, Poderes y regiones: problemas en la constitución de la nación colombiana, 1810-1850, Medellín, Universidad de Antioquia, 1987, y también Christopher Abel, Conservative Politics in Twentieth-Century Antioquia (1910-1953), Occasional Paper III, Oxford, Latín American Centre, St. Anthony's College, 1973, pp. 4-5

9 Como la mayoría de este artículo, esta nota se remite a mi tesis doctoral, Liberalism and Conflict in Socorro, Colombia, 1830-1870, Duke Universitv, Ph.D. tesis, 1991, capítulos 2 v 3. La tesis está disponible en la Biblioteca Luis Ángel Arango, y también en el Archivo General de la Nación. 
cual tengo cierta familiaridad, para examinar cómo las ironías antes invocadas contribuían al ordenamiento de la política regional, bajo el contexto de un estado central relativamente débil en todo momento- quizás la ironía más grande de todas.

La provincia del Socorro, que tenía una población aproximada de 160.000 habitantes al llegar al medio siglo, fue una región de colonización relativamente tardía y difusa, con una población abrumadoramente blanca/mestiza, una economía agrícola/artesanal, vínculos relativamente débiles con los mercados extrarregionales (y mucho menos extranjeros), y con unas élites locales bien diversas pero generalmente no-señoriales. En fin, más o menos la visión general difundida por Manuel Ancízar en su famosa Peregrinación de Alpha [1852], aunque en un trabajo más extenso he buscado matizar un poco sus conceptos. ${ }^{14}$ Lo que a continuación viene es un intento de seguir el hilo de la organización estatal en el Socorro, desde la época de la Independencia hasta más o menos el año 1870. Para la época de 1810 hasta 1850, el enfoque recaerá sobre la primera ironía, la del federalismo versus localismo; para la época de 1850 hasta 1870, el enfoque recaerá sobre la segunda, es decir, ¿qué tipo de estado le conviene a qué tipo de ideología y programa generales? Las dos partes contribuyen al esclarecimiento de la tercera ironía, la existencia de centralistas en provincia. ${ }^{15}$

\section{ORGANIZACIÓN ESTATAL Y PODER LOCAL EN EL SOCORRO, 1810-1850}

El aspecto dominante de la vida política en el Socorro durante la Colonia y primeras décadas de la República, fue el conflicto entre pueblos jurídicamen-

14 La versión de Ancízar tiene un peso historiográfico tanto más importante, porque fueron muy contados los viajeros que dejaron escritos sobre su paso por la provincia-el trafico Bogotá-Cúcuta pasó preferencialmente por la ruta Tunja-Sogamoso-Málaga-Pamplona, hasta después de la Guerra de 1860. La Peregrinación es un modelo del genero, pero sufre necesariamente de la subjetividad moralizante del autor; además, la rapidez de sus paradas locales le hizo prisionero de sus anfitriones del momento. Para un bosquejo más extenso sobre la situación socioeconómica del Socorro entre la Independencia y el medio siglo, véase Stoller, Liberalism and Conflict, capítulos 3 a 5.

15 Aquí es necesario señalar que la primera ironía sigue vigente a lo largo del siglo, y sigue vigente hoy, por ser una característica estructural de casi todos los federalismos conocidos, hago énfasis en ésta para el período 1810-1850 por considerar que allí tiene su mayor peso relativo. La segunda ironía corresponde preferencialmente a los períodos de más candente debate ideológico, y para el siglo XIX la época desde la administración López hasta la llegada a escena del nuñismo, durante los años 70 , representa la cumbre de aquel debate.

\section{$-16-$}


llos regionales que vieron la incapacidad del estado central para derrotar a la rebelión (esa sí auténticamente regionalista) de Obando, más que la expresión de anhelos autonomistas a lo largo del país. ${ }^{10}$ (Una lectura de los pronunciamientos regionales siempre me produce cierto acuerdo con el cronista ultracentralista José Manuel Restrepo, quien los calificó de pura palabrería sin programa). ${ }^{11}$ Una década más tarde, el empuje protofederalista del medio siglo, coronado por la "Lei de descentralización de rentas i gastos" de 1850, aparece como producto de la inminente quiebra presupuestal del estado central; otra vez los anhelos de provincia tenían una incidencia mucho menor, como lo reconocieron varios liberales de la época. ${ }^{12} \mathrm{Y}$ para finales de la década de los 50, el "federalismo desde arriba" fue reforzado por la estrategia partidista: los jefes nacionales de los dos partidos (siendo Murillo y Ospina los casos más famosos al respecto) buscaron refugios seguros a nivel regional, Santander y Antioquia respectivamente, en caso de no poder consolidar su control sobre el estado central. ${ }^{13}$ Esta interpretación no carece de validez por estar, en apariencia, centrada en el papel ejercido por Bogotá, pues aunque sería elegante que una interpretación del federalismo se basara en el peso de las regiones, la elegancia no siempre se encuentra en la realidad histórica. Pero esta versión "desde arriba" es incompleta, y se vuelve mucho más dinámica e interesante cuando se incorporan los niveles subalternos de región y localidad. En las páginas siguientes trataré de bosquejar el caso del Socorro, con el

10 Creo que esta interpretación fue abrazada implícitamente por Robert Gilmore, en su obra Federalism in Colombia, 1810-1858, Univcrsity of California, Ph.D. tesis, 1949, recién publicada en Colombia: nótese que Gilmore casi no menciona la rebelión (pp. 169-175), lo cual sugiere que la considera de poca importancia para una historia del federalismo granadino; véase también Bushnell, Making of Modera Colombia, pp. 91-92.

11 José Manuel Restrepo, Diario político y militar, 4 ts., Bogotá, Imprenta Nacional, 1954, t. 3, pp. 180 181.

12 Salvador Camacho Roldán, Memorias de Salvador Camacho Roldan, Medellín, Ed.-Bedout, s/ f, pp. 161-163; véase también el informe del Gobernador del Socorro José Leiva, publicado en la Gaceta Oficial, 2 enero 1849, y Eran k Safford, Commcrce and Industry in Central Colombia, 1821-1870, Columbia University, Ph.D. tesis, 1965, p. 134.

13 Lo cual constituye una variación interesante sobre la interpretación "sour grapes" del federalismo, a su vez la versión más extrema del instrumentalismo: es decir, que el federalismo es recurso inevitable de los perdedores a nivel nacional, para (a) atrincherarse regionalmente mientras procuran recuperar e! poder nacional, y (b) tener un tema de arranque para su campaña política-militar de reconquista nacional. En este caso, los dos partidos se portaron simultáneamente como perdedores, estrategia cautelosa y muy ajustada a la incertidumbre reinante de la época. También hay que resaltar que el federalismo de 1857 respondió a firmes convicciones, de lado y lado, de que las bondades de sus respectivas ideologías serían públicamente demostradas en las "vitrinas" de los nuevos estados, especialmente Santander y Antioquia. (Véase el "Informe del presidente del nuevo Pistado de Santander", Manuel Murillo Toro, en Marco Antonio Estrada, Historia documentada de los primeros cuatro años de vida del Estado de Santander, Maracaibo, Ecos del Zulia, 1893, p. 307). 
MAPA DE LA PROVINCIA DEL SOCORRO. 1850

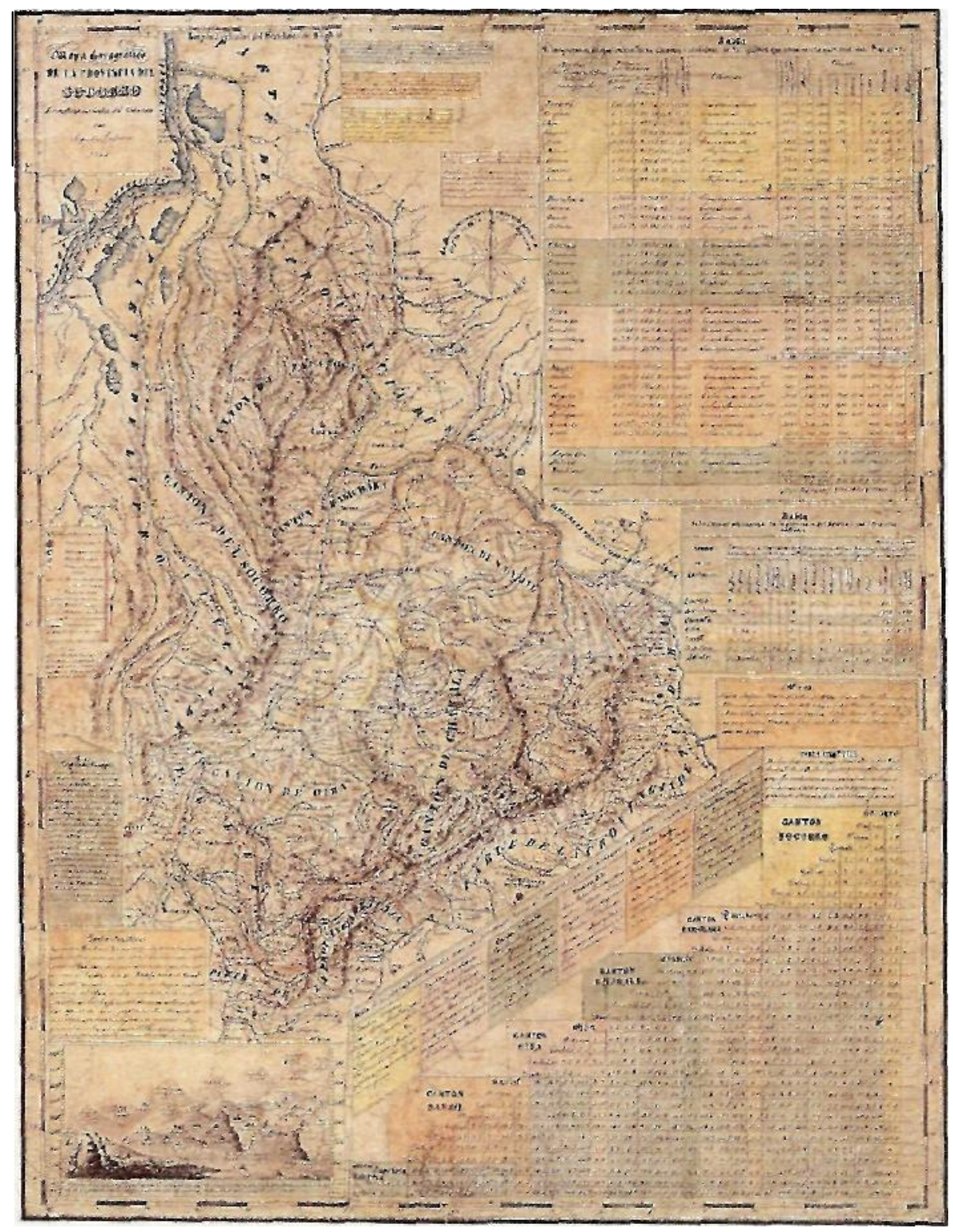

Fuente: Archivo General de la Nación, (Bogotá), Mapoteca 6, ref 23

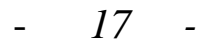


te reconocidos ("erigidos"), o entre estos y asentamientos que buscaban tal reconocimiento. Desde las fundaciones iniciales de las últimas décadas del siglo XVII, ningún asentamiento pudo solicitar la erección, ni la mejoría de su condición jurídica una vez reconocido, sin provocar la oposición (a veces encarnizada) de las jurisdicciones circundantes. Estos conflictos eran más que simples pleitos leguleyos, aunque necesariamente asumían esa forma, dada la naturaleza legal-administrativa del asunto; y los intereses involucrados no se limitaron a una fronda tinterillesca, aunque la influencia desproporcionada de aquella fronda es bien evidente en determinados casos. ${ }^{16}$ Los conflictos tocaban a las bases mismas de la identidad colectiva, en una región donde las categorías sociales investidas de fuerza jurídica no tenían mucha aplicación (ej. indígenas, negros esclavos), y carente de idiomas de identidad local que no fueran la jurisdicción territorial misma (como hubiera podido conseguirse de grandes haciendas señoriales, resguardos y otras modalidades de propiedad comunitaria, o de migraciones en grupo, tipo antioqueño). Más estos conflictos casi siempre giraban en torno a cuestiones presupuestales, y así eran ligados al factor estructural más importante de la economía regional de la época, la escasez de numerario producida por la falta de mercados extrarregionales. ${ }^{7}$

A partir de la Independencia, estos conflictos se categorizan del siguiente modo:

1) La sempiterna rivalidad entre Socorro (pueblo) y San Gil, dos centros de tamaño más o menos equivalente, por la hegemonía regional. ${ }^{18}$

2) Conflictos entre pueblos de segunda categoría, en busca del status de sede cantonal, lo cual conllevaba la hegemonía subregional, cierta autonomía presupuestal, especialmente en cuanto a obras públicas, y preferencia en la ubicación de instituciones nacionales "de circuito," como juzgados, notarías y oficinas de registro, etcétera. (Ej.: Barichara/Zapatoca en el norte de la provincia, Oiba/Charalá en el sur.)

16 En un momento de frustración, el gobernador Urbano Pradilla observó que "estas pretenciones [sobre traslado de veredas entre distritos menores) son siempre las de un solo individuo que reune jentes; las hace firmar lo que él quiere, i de este modo aparece como solicitud de un pueblo lo que únicamente es el capricho del uno solo." Pradilla al Secretario de lo Interior, Socorro, 10 septiembre 1846, Archivo General de la Nación (en adelante AGN), República, Gobernaciones Varias, 123, f. 717.

17 Obviamente estos conflictos no se limitaban al Socorro, ni al nororiente en general (donde hay casos sonados como Málaga-Concepción, y la enredada competencia entre Bucaramanga, Girón, Floridablanca, y Picdecuesta), y sería atrevido decir que el Socorro los tiene más y mejores. Faltan los estudios regionales que nos permitirán hacer comparaciones seguras sobre este y demás temas.

18 Véase la tesis de Mónica Cortés Yepes, Poder y conflicto en el siglo XVIII: El caso San Gil-Socorro, Bucaramanga, Escuela de Historia, Universidad Industrial de Santander, 1993, y Stoller, Liberalism and Conflict, pp. 41-44, 153-158, etc.. 
3) Conflictos entre pueblos de tercera categoría (meros distritos, no cabeceras de cantón) y los de primera o segunda, para lograr una mejoría de status, o sobre cuestiones particulares como acceso a instituciones cantonales. (Ej.: Pinchote/San Gil, Robada [Galán]/Zapatoca, Coromoro/ Charalá, Suaita/Oiba).

4) Conflictos entre pueblos de tercera categoría, sobre linderos y vecinos, con la viabilidad misma de los pueblos (en cuanto a contribuyentes para el servicio local, vecinos para los cargos concejiles, etcétera) en la balanza. (Ej.: Curití/Aratoca, Cunacua (Olival)/Guadalupe, Robada (Galán)/ Palmar, Cincelada/Coromoro). ${ }^{19}$

La incidencia de estos conflictos en el ordenamiento de lealtades definidas por el centralismo/federalismo se evidencia durante la época de la Independencia, como bien lo describe Margarita Garrido (con enfoque temático y geográfico más amplio) en su reciente libro; ${ }^{20}$ para el Socorro, bien podría decirse que estos conflictos le aportan lo Boba a la Patria Boba. Socorro (pueblo), que desató el movimiento protoindependentista en el nororiente con el derrocamiento del corregidor Valdés en julio de 1810, pronto se declaró por un "federalismo" que en la práctica asumió una soberanía casi total frente a la Junta Suprema de Bogotá; mientras tanto, la junta del Socorro desconoció los privilegios fiscales y administrativos de los demás pueblos de la provincia. Las viejas pretensiones de villa, ahora fortalecidas por nuevas ideas de "soberanía," producían un proceder (y un tono) bastante soberbio. Esta actitud propietaria, que se extendió por medio de advertencias a Bogotá y Tunja contra el pretendido "robo" de "sus" pueblos, muy pronto generó el enojo de San Gil, antiguo agresor en la rivalidad Socorro-San Gil, ahora convertido en víctima. Antes de finalizar el año 1811, San Gil logró salirse del dominio del Socorro, aliándose con el centralismo de Antonio Nariño en Bogotá, con consecuencias fatales para la Junta del Socorro. ${ }^{21}$

Para los pueblos menores, especialmente de las franjas sur y nororiente (que no tenían fronteras "naturales" con las provincias vecinas), la coyun-

19 Stollcr, Liberalism and Conflict, pp. 159-60, 166-167, 174-178.

20 Margarita Garrido, Reclamos y representaciones: variaciones sobre la política en el Nuevo Reino de Granada, 1770-1815, Bogotá, Banco de la República, 1993, pp. 316-332.

21 Horacio Rodríguez Plata, La antigua provincia del Socorro y la Independencia, Bogotá, Eds. Bogotá, 1963, sigue siendo la versión indispensable; los documentos claves incluyen al Auto de la Junta del Socorro, 2 noviembre 1810, AGN, Anexo-Historia, 11, f. 266 v siguientes; Junta del Socorro a Camilo Torres, 24 diciembre 1810, AGN, Anexo-Gobierno, 18, f. 965, y la "Protesta" de la Junta, 28 enero 1812, Archivo de la Notaría Primera (Socorro), 1812 (I), ff.16-17. Para el conflicto Socorro-San Gil, véase Cabildo a la Junta, San Gil, 7 agosto 1811, AGN, Anexo-Historia, 12, ff. 554-555, y 22 marzo 1811, Anexo-Gobierno, 19, f. 55 y siguientes. Estas citas dan una pálida idea de la riqueza de los dos fondos Anexo del AGN para la Patria Boba en el Socorro. 
tura de 1810 trajo la oportunidad de ofrecer sus lealtades a la junta que más garantías y privilegios ofreciera (entre las del Socorro, Tunja, y Bogotá), con su adhesión nominal a la causa federal o centralista como contraprestación. Por ejemplo, en octubre de 1810, el distrito de Petaquero (hoy San Joaquín, entre Mogotes y Onzaga) instruyó a sus apoderados en el sentido de que firmaran un convenio con la primera entidad superior que le garantizara plena autonomía fiscal, más privilegios para el vecino (y más grande) pueblo de Soatá, y el derecho incondicional de obedecer "solo en lo justo." ${ }^{22}$ Varios pueblos escogieron la opción centralista (de Bogotá) sin probar suerte con la Junta del Socorro, evidencia de su escepticismo frente al federalismo a la socorrana; los emisarios de la Junta a los pueblos del sur de la provincia, como Pare y Moniquirá, se portaron como agentes de un poder foráneo, y fueron recibidos en la misma forma. ${ }^{23}$ Un federalismo más o menos duradero sólo llegó al Socorro con el colapso parcial del régimen centralista a mediados de 1812 (gracias a peleas intestinas entre la dirigencia bogotana, más que a presiones provinciales), y su caída final en 1814.

Bajo las Constituciones de 1821 y 1832, las provincias eran artefactos administrativos para canalizar la autoridad central; no eran órganos de autoridad regional. Los gobernadores fueron nombrados por Bogotá, las rentas provinciales eran minúsculas, y las cámaras de provincia gastaban su tiempo en asuntos de poca importancia- como las Asambleas Departamentales antes de la Constitución de $1991 .^{24}$ Lo sorprendente, dada la reputación "federalista" ya asociada con el Socorro en la imaginería política nacional (es decir, en Bogotá), es que este estado de cosas parece no haber suscitado mayores inconvenientes para los pueblos de la provincia, hasta la Guerra de los Supremos. Con muy contadas excepciones se buscan en vano las peticiones federalistas en el Archivo del Congreso, o los discursos federalistas

22 Actas de Mogotes (10 septiembre 1810) y Petaquero (29 septiembre 1810), en Archivo Histórico de San Gil (en adelante AHSG), Protocolos de San Joaquín 1802-1810, 32-35v, 37-38v, y Protocolos de San Joaquín 1811-1815, 1 -30.

23 Por ejemplo, Alberto José Montero y José Romualdo Sobrino a la Junta Suprema, Pare, 20 septiembre 1810, AGN, Anexo-Gobierno, 18, ff 963-967; nótese que la mayoría de los pueblos tratados en este documento vinieron a formar parte de la provincia de Vélez cuando se creó en 1832.

24 Véase las constituciones y comentarios en Manuel Antonio Pombo y José Joaquín Guerra (comps.), Constituciones de Colombia, 2 ts., Bogotá, Imp. de La Luz, 1911, t. 2, pp. 869-1002; para aspectos fiscales, Stoller, Liberalism and Conflict, pp. 129-133. 
de los prohombres del "progresismo" socorrano, liderados por Vicente Azuero. $^{25}$

Quizás esta falta de actividad se debió al deseo de no perder el tiempo en temas que no prometían éxito, dado el antifederalismo de todos los presidentes desde Bolívar y Santander a Mosquera, pero hay otro motivo importante: la naturaleza del centralismo, y la distancia de Bogotá, permitían el mantenimiento del equilibrio regional, dando a los reclamos y conflictos locales un trato "salomónico" proveniente del desdén de quienes tomaban a diario decisiones de peso sobre tierras desconocidas. Por ejemplo, la idea de dejar la Gobernación en Socorro (pueblo) y erigir la corte de apelaciones en San Gil, es algo que difícilmente se habría confeccionado por los mismos provincianos, pero sirvió para calmar una rivalidad que entró a la época republicana en estado hirviente. ${ }^{26}$

La distancia, relativa indiferencia, y pésima información de que disponía Bogotá sobre la vida provinciana ${ }^{27}$ - especialmente sobre una provincia como el Socorro, que poco aportaba al fisco nacional, además de su consumo de productos estancados como sal, tabaco, y aguardiente- se constituían en una feliz combinación para muchos peticionarios socorranos. Individuos, veredas, y pueblos menores lograban ajustes favorables (aunque inevitablemente perju-

25 Hay contadas excepciones, como una petición (de dudosa sinceridad) de los vecinos ciel Socorro, proponiendo el federalismo como medida para impedir la salida de Venezuela de la Gran Colombia, fechada 29 abril 1830, en AGN, Fondo Ortega Ricaurte, 239-1, ff. 1-2; y la más creíble (pero abstracta e histriónica) de la Cámara Provincial con fecha 5 de octubre de 1838 (es decir, en plena campaña progresista contra la Administración Márquez), en la Bandera Nacional, 4 de noviembre 1838). Azuero evitó cualquier olor a federalismo en su folleto de propuestas reformistas de 1835, y en su informe de marzo 1840 sobre reformas constitucionales; los documentos están en Guillermo Hernándcz de Alba, Documentos sobre el Doctor Vicente Azuero, Bogotá, Imprenta Nacional, 1944, pp. 333-342, y Oscar Delgado (comp.), Francisco de Paula Santander y Vicente Azuero, Antología política, Bogotá, Colcultura, 1981, pp. 365-372.

26 "Los cabildos de San Gil, Vélez, Barichara, Charalá, Zapatoca, y Moniquirá en la provincia del Socorro solicitan la traslación de su capital a la villa de San Gil" (1824), AGN, Secretaría de lo Interior, 151, ff. 875-890; Tribunal Superior de San Gil 150 años 1835-1985, Bucaramanga, Contraloría Departamental, 1985.

27 Ejemplo extremo pero ilustrador: en 1842, después de varios meses de preguntarse por qué la Gobernación siempre recibía una Gaceta menos de lo necesario para repartir a las alcaldías, el Gobernador Zaldúa y la Secretaría de lo Interior decidieron cuadrar cuentas, y resultó que Bogotá no supo de la existencia del distrito de Coromoro (zona de colonización del cantón Charalá), erigido por el Congreso en 1834 y prontamente olvidado. Francisco Javier Zaldúa al Interior, Socorro, 28 noviembre 1842, AGN, República, Gobernaciones Varias, 83, ff. 425-426. Quién sabe si los ocho años entre su erección y su "descubrimiento" constituyeron una Edad Dorada de autonomía local para los coromoros.

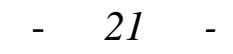


diciales para sus colindantes, en el juego "cero-suma" de linderos y privilegios), utilizando la persistencia, la exageración, la fingida indignación patriótica, y una buena letra: en fin, la hoja de vida de un buen tinterillo, pero una estrategia también abierta a cualquier socorrano medianamente letrado. Muchas peticiones a favor del arreglo de linderos aprovecharon la falta de conocimientos geográficos del estado central, invocando distancias enormes u obstáculos insorteables, usualmente exagerados o inventados. ${ }^{28}$ La centralización era tal, que aún cuando Bogotá le pedía informes al gobernador provincial sobre un asunto, éste usualmente no disponía de las herramientas necesarias para hacer las averiguaciones. ${ }^{29}$ Otro aspecto interesante es que los pueblos de segundo y tercer orden podían apelar al espíritu antifederalista de los regímenes nacionales para impedir la hegemonía regional de Socorro y San Gil, como en 1827 cuando varios cantones pedían que los concejos cantonales asumieran las funciones de juzgados de segunda instancia- supuestamente como medida de economía, pero de hecho una devolución de poder judicial desde la instancia provincial hacia abajo."

Cuando la provincia se lanzó en rebelión contra el ya debilitado régimen de José Ignacio Márquez en septiembre de 1840, su "Jefe Supremo" (y ahora declarado federalista) fue el mismo gobernador, Manuel González, quien durante tres años de administración había batido todos los récords sobre la microgerencia de los asuntos locales: solía revisar y anular los acuerdos más insignificantes de cabildos pueblerinos, y apoyó la abolición completa de los cabildos en los pueblos no cabeceras de cantón. ${ }^{31}$ La corta duración del régimen rebelde del "Estado del Socorro" no nos permite una plena y segura caracterización de su programa, pero sí se puede notar (anticipando un poco la se-

28 Es de recordar que estamos hablando de la época pre-Codazzi, es decir, carente de mapas confiables sobre la región que le proporcionaran a Bogotá datos fidedignos sobre distancias V obstáculos; los planos utilizados antes de los años 50 usualmente fueron levantados según las necesidades del caso, v por las parres en conflicto, con rodas las deformaciones previsibles.

29 Hasta los jefes políticos (ejecutivo cantonal) frecuentemente dijeron no saber nada sobre las personas principales de los distritos subalternos de su jurisdicción, para fines de nombramientos: ej., Rafael María Ramírez ai Gobernador, Socorro, 9 julio 1842, AGN, República, Gobernación del Socorro, 9, ff. 259-260, y ternas de 26 abril 1834 y 14 agosto 1839, Gobernación del Socorro. 4, f. 266, 6, ff. 774776.

30 "Expediente formado por las municipalidades del Socorro, sobre la reforma de varias leyes" (1827), AGN, República, Congreso, 25, ff. 852-874.

31 Hay docenas de acuerdos vetados por González en AGN, República, Gobernaciones Varias, r. 71 (años 1838 v 1839), frente a muy pocos por sus antecesores (ej., t. 53, f. 791, bajo Pablo Durán, 1837) o sucesores (ej., t. 91, f. 760 y t. 111. f. 352 , gobernaciones de Domingo Mutis y Urbano Pradilla, 1843 y 1844). 
gunda ironía) una tensión entre el "federalismo" de hecho del nuevo régimen seccional (y sus semejantes en las demás provincias rebeldes), y la plataforma ideológica general de los "progresistas" liderados desde Bogotá por Vicente Azuero: este último tenía la bien fundada preocupación de que una cadena de regímenes de "supremos" a lo largo del país sería la antítesis del gobierno fuerte, reformista, y (más que todo) civilista que el partido santanderista (más allá del mismo Santander) anhelaba.

Más al grano de la primera ironía, es significativo que una de las primeras (y únicas) medidas administrativas del "listado del Socorro" fue la revocación del status de cantón ganado por Oiba en 1836: una clara expresión de la hegemonía de Socorro (pueblo), pues aquel cantón fue creado quitándole territorio al de Socorro. Además de ser un nuevo episodio en la pugna Socorro-Oiba (o, más estrechamente, la pugna entre la familia Tavera, de Oiba, y la élite socorrana), la medida puede apreciarse como una contraofensiva socorrana contra San Gil, que había apoyado las pretensiones cantonales de Oiba como parte de su estrategia para disputarle a Socorro la hegemonía regional. ${ }^{33}$ Parece que la participación en la rebelión, aunque superficialmente igual entre Socorro y San Gil, tenía matices profundamente distintos: para la clase dirigente de Socorro, representó la oportunidad de reconstruir una hegemonía política regional debilitada por los sacrificios de la Independencia y por la crisis económica, a base de ser Socorro el epicentro de la rebelión; para la de San Gil, representó un momento ideológico, la victoria del progresismo tipo Azuero (quien era socorrano y no sangüeño, como una ironía más), más que un proyecto regionalista. ${ }^{34}$ Desde el punto de vista historiográfico, es una lástima que la rebelión fracasó tan pronto en los campos de Buenavista y Aratoca, pero no es aventurado especular que las tensiones Socorro-San Gil, y el "centralismo a nivel regional" en general, pronto habría provocado una crisis en el estado rebelde, como pasó efectivamente durante la Patria Boba, y también durante la Rebelión Comunera de 1781. (No sorprende que Oiba se convirtió en fortín antirebelde, y se consolidó como el único pueblo "ministerial" [protoconservador] de la provincia.)

32 Vicente Azuero a [Juan Nepomuceno Azuero?], sin fecha, en José Manuel Restrepo, Historia de la Nueva Granada, 2 ts., Bogotá, Ed. Cromos, 1952, t. 1, pp. 389-392.

33 Miguel Saturnino Uribc al Interior, Socorro, 13 agosto 1841, AGN, República, Gobernaciones Varias, 76, ff. 689-692; declaración del jefe político de Oiba, 3 junio 1842, Gobernaciones Varias, 91, £387.

34 El Día (Bogotá), 10 octubre v 26 diciembre 1841; Enrique García al Secretario del Interior, Socorro, 24 abril 1841, AGN, Gobernaciones I arias, 76, f. 283, y Alfonso Acevcdo al Secretario, Socorro, 30 abril 1841. Gobernaciones Varias, 76, f. 309; fosé María Afanador al presidente Herrán, Pamplona, 12 agosto 1841, Archivo del Genera/ Pedro Alcántara Herrán, Academia Colombiana de Historia. 
Es solamente después de la inesperada victoria gobiernista, que el reputado federalismo de la provincia del Socorro comienza a adquirir cierta sustancia, aunque muy limitada: el federalismo como consigna llega a resumir todo el resentimiento regional de pertenecer a una facción derrotada, y a un partido más minoritario que nunca entre la clase política a nivel nacional. En la boca de exrebeldes como Ricardo Roldán de Charalá, y del tribunal regional de apelaciones (un fortín de oposicionismo, según el diario ministerial El Día), el "federalismo" representó el rechazo a un gobierno central "inútil" que les habló a los pueblos "como imbéciles i como niños a quienes se les engaña con palabras i se alucina con halagos pueriles." ${ }^{35}$ A primera vista sorprende que el gobierno no tuvo inconvenientes en publicar estos agrios comentarios (sobre el proyecto de Constitución de 1843, muy centralista) en la Gaceta, pero su publicación demuestra que el gobierno los tomó como flechazos meramente partidistas, y no como la expresión de un federalismo coherente: el pronto regreso de la élite regional a las filas del orden (aunque no del "partido del orden," el ministerial), y el regreso a la "balanza de fuerzas subregionales" que caracterizaba a la anterior época centralista (ver arriba), confirmaron este análisis perspicaz. ${ }^{36}$ Sin embargo, los años cuarenta son importantes porque la entrada en escena del federalismo como elemento discursivo a nivel regional fue un paso necesario hacia cosas más concretas.

Cuando los primeros pasos hacia la descentralización (que sus proponentes en Bogotá jamás caracterizaron como federalismo sino después de 1853, vale decir), comenzando débilmente en 1848 y culminando con la "Lei de descentralización de rentas i gastos" en 1850, las voces políticas de la provincia del Socorro se ufanaban de haber figurado decisivamente en la transición, cosa que poco o nada tenía que ver con la realidad, como indiqué más arriba. Lo interesante, y lo relevante como una especie de "prueba experimental" de lo que acabo de sostener sobre las ventajas del sistema centralista para la paz provinciana, es que los pronósticos optimistas sobre la descentralización, vertidos por la Cámara Provincial (en el sentido de que las medidas traerían "la fusión de los partidos" en la provincia, es decir, de las rivalidades pueblerinas, va que todavía no existía pugna de partidos propiamente dicha), resultaron vanos."

35 Gacela de la Nueva Granada, 14 noviembre 1841, 20 febrero, 22 mayo, 5, 12,19 junio 1842.

36 El Día, 28 enero 1844; Gobernador Francisco Javier Zaldúa al Presidente Herrán, Socorro, 4 y 15 enero 1843, Archivo del General Pedro Alcántara Herrán, Academia Colombiana de Historia.

37 El Demócrata (Socorro), 14 abril 1849; un comentario más pesimista es "Ideas lugareñas o de localidad," El Demócrata, 8 diciembre 1849. 
La medida principal de la Ley de 3 de junio de 1848 fue la eliminación del papel fiscal de los cantones, a favor de las provincias- en sí, un ejemplo de fortalecimiento provincial a expensas de las jurisdicciones subregionales. Las provincias tenían el derecho de quedarse con los nuevos tributos y recursos, o de pasarlos a los distritos. El tema fue especialmente espinoso porque el cantón de San Gil disfrutaba de recursos excepcionales frente a los demás cantones (gracias a su manejo de obras rentables como el puente sobre el río Fonce en San Gil, y la cabuya sobre el río Chicamocha en Jordán/Sube), y por una disposición especial del Congreso, controlaba el importante Colegio de San José de Guanentá en San Gil. Los diputados del cantón Socorro a la Cámara Provincial abogaron por la provincialización, mientras los de San Gil propusieron "juntas administrativas" a nivel cantonal, de hecho una continuación del sistema anterior; ganaron los primeros, pero San Gil se ganó el manejo (como distrito) del colegio y del hospital. Esta victoria parcial resultó serle políticamente costosa a San Gil, porque produjo el enojo de los pueblos subalternos del cantón, cuyos vecinos principales habían aportado fondos y créditos a las dos instituciones (especialmente durante los años veinte) con la garantía de que serían entidades cantonales. ${ }^{38}$ La ley también le permitió a las provincias establecer la contribución directa, medida ensayada y prontamente desechada por Bolívar poco después de la Independencia, y no menos aborrecida por los contribuyentes del medio siglo. La forma en que la Cámara Provincial estableció el nuevo impuesto confirmó las tendencias ya mencionadas: se limitó a publicar una lista de distritos con las sumas que habían de recaudarse en cada uno, una modalidad rechazada por los contribuyentes (especialmente por su parecido a los "empréstitos forzosos" de los tiempos de guerra), y por los cabildos que se vieron reducidos a ejecutar las mal pensadas cuotas distritales. ${ }^{39}$ No debe sorprender, pues, que la ola mayor de descentralización, en 1850, puso en juego la existencia misma del Socorro como provincia. Durante las sesiones de aquel año, el Congreso examinó varias solicitudes de todos los rincones del país, pidiendo la división de provincias, pero las peticiones del Socorro fueron únicas: provincias como Pamplona o Panamá (que pidieron, y recibieron, la división) eran enormes y fácilmente divisibles

38 No tenemos sino una versión posterior y polemizada de estos importantes debates: Evaristo Azuero, "Una contestación" y "Otra contestación", El Neo-Granadino, 17 mayo y 17 octubre 1850; para el Colegio, véase los comentarios de Gonzalo Tavera, en el Diario de Debates, Bogotá, 20 abril 1850. Nótese que la posterior Ley (nacional) de 30 mayo 1849 eliminó la opción de provincialización, transfiriendo los recursos y propiedades ex-cantonales a los distritos: Codificación Nacional, 34 ts., Bogotá, Imp. Nacional, 1924-54, t. 13, pp. 439-445, y resolución del Cabildo de San Gil, 24 junio 1849, AHSG 770.

39 Mensaje del gobernador Zoilo Silvestre a la Cámara Provincial, 10 febrero 1849, AGN, Gobernaciones Varias, 154, ff. 836-839. 
según fronteras geográficas o económicas, pero el Socorro era una jurisdicción relativamente compacta, con "usos y costumbres" tan uniformes que el socorrano ya era un "tipo regional" ampliamente conocido en el país. ${ }^{40}$ El problema de la provincia, como lo señaló el congresista Evaristo Azuero (del pueblo de Socorro), fue su historia de querellas intestinas, especialmente entre Socorro y San Gil: cuando Azuero dijo en la Cámara que San Gil siempre había sido una "rémora" para el progreso de Socorro, los sangüeños respondieron con una arremetida verbal contra las "pasiones bastardas" del cantón vecino, que dejó confundidos a los congresistas de otras provincias, que no entendieron cómo una provincia aparentemente tan uniforme (y tan "liberal") pudo albergar tantas rencillas lugareñas. ${ }^{41}$ Que la provincia no salió dividida en 1850 se debió a dos factores. El más inmediato fue la complejidad de los conflictos, que produjo una serie de planes incompatibles sobre las fronteras de la división (norte/sur, versus la simple escisión del cantón San Gil) y sobre la capital de la nueva provincia norteña (cuyos otros cantones vieron con disgusto la posibilidad del altanero San Gil como capital de provincia). Pero 1850 también fue el año clave en dos procesos paralelos que pronto cambiarían la faz del tema: la creciente "socialización" de la ideología liberal (en el sentido amplio de preocuparse por las cuestiones sociales, con un discurso radical y a veces clasista), y el rápido crecimiento del enfrentamiento partidista. Estos dos procesos, obviamente ligados pero no idénticos, trajeron a la cuestión de la organización estatal una nueva importancia para los dirigentes nacionales, y también para las élites locales.

\section{PROGRAMA LIBERAL Y RÉGIMEN FEDERAL, 1850-1870: UNA PERSPECTIVA DESDE SAN GIL}

Como anoté más arriba, San Gil era un pueblo identificado con el progresismo tipo Santander/Azuero, y con el aspecto más ideológico de la rebelión de 1840. Esta identificación llegó al medio siglo con el liberalismo, en las figuras de José Hilario López y (más ambiguamente) Florentino González. La élite sangileña encontró mucho qué elogiar en el programa reformista de la "Administración del 7 de marzo," como la extinción del monopolio tabacalero y

Camacho Roldan, Me/norias, pp. 194-195; Diario de Debates, 10 y 11 abril, 18 y 21 mayo 1850; varias peticiones en Archivo del Congreso, 1850, Cámara-Proyectos de Ley Pendientes (1-2-3o. Debates), pp. 363-406.

41 Rito Antonio Martínez, "Al público, y especialmente a mis comprovincianos," El Neo-Granadino, 4 mayo 1850; petición de vecinos de San Gil al Congreso, en el fondo citado en la nota anterior, ff. 394396; comentarios de un congresista liberal de Cartagena, en Diario de Debates, 11 abril 1850. 
la privatización (tantas veces demorada) de los apetecibles ejidos de Guane, además de la obvia vindicación de su trayectoria política desde 1832. Pero este patriciado compacto y seguro de sí mismo, liderado por jóvenes como Rito Antonio Martínez y figuras más venerables como Juan de Dios Silva, ${ }^{42}$ pronto se vio desafiado en su hegemonía local y cantonal por dos crisis originadas por la victoria liberal de 1849. La primera fue la pretendida división de la provincia, algo que la dirigencia sangileña deseaba (Martínez fue el ponente de uno de los proyectos en el Congreso de 1850), pero los debates le mostraron al país político un rostro prepotente y poco agradable de San Gil, algo que sus enemigos a nivel provincial aprovecharon hábilmente en la prensa bogotana. ${ }^{43}$ Que la dirigencia de Socorro (pueblo y cantón) se alineara en su contra no fue nada nuevo; pero un nuevo espíritu de rebeldía en los cantones de Barichara y Zapatoca, y hasta en los mismos distritos subalternos del cantón San Gil, sí fue preocupante, y la derrota de todos los candidatos sangileños en las elecciones legislativas de 1850 (agosto) confirmó que San Gil va no pudo contar con la amistad política de sus antiguos aliados en la región. ${ }^{44}$

Más importante aún, y la verdadera fuente del cuestionamiento que la élite sangileña después haría de su identidad liberal, fue el auge de un pequeño pero ruidoso movimiento popular en San Gil, una Sociedad Democrática de Artesanos liderado por el cura y político José Pascual Afanador. ${ }^{45}$ Luego de gastar casi todo el año de 1851 en una ruda polémica con la Sociedad, v con Afanador después de disuelta la Sociedad, el cabildo de San Gil (encabezado por Martínez) se quejó a Bogotá sobre los "brotes de indisciplina" que ya eran cosa diaria, fruto en su concepto de la retórica radical y de la filosofía del "dejad-hacer" provenientes de la capital. Su solución, como buenos (pero va

42 Véase Stollet, Liberalism and Conflict, pp. 237-249.

45 Evaristo Azuero, "Una contestación" y "Otra contestación," El Neo-Granadino, 10 mavo y 10 octubre 1850; Unos socorranos, "Algo más sobre elecciones del Socorro," El Neo-Granadino, 17 octubre 1850. La respuesta arrogante de la clase política de San Gil, "Ya es preciso hablar," publicado en El NeoGranadino, 6 enero 1851, no fue muy ajustada al ambiente retórico del medio siglo bogotano.

44 Resultados en el Archivo del Congreso, 1850, Senado-Informes de Comisiones 4, ff. 271 -272 y Cámara-Informes de Comisiones, 7, ff. 172-181, analizados en Stoller, Liberalism and Conflict, p. 229.

45 El episodio está bosquejado en Stoller, Liberalism and Conflict, capítulo 7; el libro de José Pascual Afanador que contiene su lado de la polémica suscitada, La democracia en Sanjil: Cartas del ciudadano José Pascual Afanador, dirijidas a la nobleza sanjileña, sobre la naturaleza i efectos de mi programa, Socorro, Imp. de Villareal i Gómez, 1851, fue reeditado en 1990 por la Gobernación de Santander, en la colección Historia Regional. La nueva edición adolece de varios defectos tipográficos, pero contiene las importantes réplicas de la élite sangileña (tildada de "nobleza" por Afanador), cuyos originales reposan en el AGN, Gobernaciones Varias, 170, ff. 98 y 106 y la Academia Colombiana de Historia, Miscelánea, 128. 
escépticos) liberales, fue algo novedoso: un aumento de autonomía local (distrital), para protegerse en lo posible de las amenazas externas al orden social local. ${ }^{46}$ Los años siguientes, culminando con el golpe de Melo en 1854- un movimiento violentamente secundado en San Gil por el artesanado ${ }^{47}$ - reforzó su idea de que el gobierno central representaba un peligro mortal, aunque ya despojado de la mayoría de sus atributos institucionales y fiscales, y a pesar de que sus medidas sustantivas eran del agrado del patriciado local.

Después de la caída del melismo, la gobernación del patriarca suaitano Lucas Caballero (gólgota a ultranza, tenaz perseguidor de melistas) le dio a la dirigencia sangileña la esperanza de que los poderes que le correspondieron a la Nación antes de la Carta de 1853 ahora podrían conferirse al nivel provincial sin mayores peligros. Este breve equilibrio fue roto estruendosamente por una nueva y extrema iniciativa federalista, otra vez venida de Bogotá como mencioné arriba. Cuando San Gil, y la antigua provincia del Socorro en general, se encontraron insertados en el nuevo Pistado de Santander que albergaba serios conflictos partidistas (en Ocaña, Vélez, y Girón/Piedecuesta/ Bucaramanga), los protagonistas de conflictos locales de tipo tradicional (es decir, de facciones personalistas o de localidad) pronto recurrieron al idioma partidista para buscar aliados a nivel extralocal, dándole a la vida política local un nuevo y amenazante aspecto que Caballero había pronosticado a finales de 1856, y que el alcalde de San Gil confirmó un año después. ${ }^{48}$ Aquí se puede apreciar el aspecto dialéctico del tema: si bien la invención del federalismo tipo 1857-58 tuvo sus orígenes en la lucha partidista a nivel nacional, la llegada del nuevo ordenamiento estatal a las regiones produjo una nueva ola de "partidización" estratégica. Es decir, lo primordial a nivel nacional es instrumental a nivel local/regional, y viceversa.

Más amenazante aún para San Gil (es decir, para la fracción mayoritaria de la élite que había pasado al conservatismo a partir de 1855, más una buena parte de la minoría que permaneció liberal) fue la naturaleza ideológica del nuevo

46 Cabildo de San Gil al jefe Político, 31 diciemdre 1951, AGN, Gobernaciones Varias, 185, ff. 519-520.

47 Stollcr, Liberalism and Conflict, pp. 272-275, basado principalmente en "Denuncio dado por Pio Peñalosa...," 1855, AHSG, 120; "Civil: el personero del distrito demanda a Juan de la Rosa Rodríguez por cantidad de pesos, 1854," AHSG, 105; Saturnino Orrega al Secretario del Tribunal Superior, San Gil, diciembre 1854, AHSG, Sección Judicial.

48 David Johnson, Santander siglo XTX: cambios socioeconómicos, Bogotá, Carlos Valencia Editores, 1984, pp. 60-62, para el ejemplo de Charalá; Lucas Caballero al Secretario de Gobierno, Socorro, 22 noviembre 1856, AGN, Gobernaciones Varias, 217, ff. 990-991; Alcalde de San Gil ai Secretario del Estado, 23 noviembre 1857, AHSG, 218. 
Estado. La Asamblea Legislativa, elegida bajo un sistema unidistrital (es decir, con una sola plancha de candidatos para el estado entero), salió compuesta de una mayoría gólgota que poco se preocupó por las consecuencias reales de su programa libertario, seguida de una minoría francamente "socialista" (lidera-da por Vicente Herrera y Gregorio García) que apelaba a las masas; el conservatismo quedó prácticamente excluido, y el liberalismo moderado (liderado por el sangileño Estanislao Silva) también fue marginado. El bloque gólgota/socialista (pues en la práctica las diferencias eran menores en cuanto a legislación) se resolvió a destruir los obstáculos locales a su agenda: en febrero de 1858 la Asamblea abolió a los cabildos, y se reservó el derecho de hacer todos los nombramientos locales y de circuito. ${ }^{49}$ La "unidad del poder," pregonado por el ideólogo liberal y presidente estatal Manuel Murillo Toro, se hizo realidad.

El nuevo periódico La Voz del Norte, de Rito Antonio Martínez, enumeró las quejas del patriciado sangüeño, conservador y aún liberal: que la contribución directa fue un instrumento de lucha de clases contra los propietarios, que Murülo estaba agitando la delicada "cuestión de ricos y pobres" sin pensar en las consecuencias funestas, que el régimen electoral estaba debilitando a los pueblos mayores y favoreciendo a los menores, gracias al gamonalismo reinante en estos últimos. Las autoridades municipales de San Gil trataron de atrincherarse-hasta el punto de cambiar las cerraduras en las oficinas públicas para impedir la entrada de la autoridad estatal, y formar una fuerza pública no oficial-pero a comienzos de 1859 ya era evidente que el federalismo liberal buscaba nada menos que el despedazamiento de las élites locales, con miramientos más ideológicos que estrictamente partidistas. ${ }^{50}$

Irónicamente- y esta vez la ironía es más bien casualidad- estas élites locales fueron rescatadas por la división partidista nacional que había originado el empuje federalista hacía dos años. Después de tres intentos fallidos de rebelión por el conservatismo santandereano, eventualmente liderado por el antiguo jefe conservador Leonardo Canal, el presidente de la Confederación, Mariano Ospina, tomó

La historia legislativa está en Estrada, Historia documentada, además de la Gaceta de Santander de la época; véase también Aquileo Parra, Memorias de Aquilea Parra, Bogotá, Imp. de La Luz, 1912, p. 139. Lamentablemente, es muy poco lo que sabemos sobre la corriente "socialista" de la época: por ejemplo, no he encontrado copia del periódico El amigo del pobre, Socorro, 1858, al parecer fue éste el órgano de aquella corriente.

50 La Voz del Norte, San Gil, noviembre 1857 - febrero 1858; véase también El Porvenir, Bogotá, órgano del conservatismo santandereano radicado en Bogotá; para la situación en San Gil, véase correspondencia en AHSG, 180, 205, y 279 (1857-1859), y Stoller, Liberalism and Conflict, pp. 307318. 
en junio de 1860 la decisión de enfrentar militarmente al gobierno de Santander, por una gama de motivos que no son del caso analizar aquí. ${ }^{51}$ Aunque las fuerzas nacionales obtuvieron una fácil victoria sobre el risible ejército estatal en la segunda batalla del Oratorio en agosto, esta guerra menor hizo inevitable la guerra grande: el general Mosquera se resolvió a invadir a Bogotá y eliminar a Ospina, y después de conseguido este objetivo, a mediados de 1861, mandó sus fuerzas a los demás reductos conservadores del país. Parece extraño hablar del "rescate" de los dirigentes locales de Santander por lo que siguió, una guerra sumamente cruenta y destructora (y con aspectos sanguinarios que hacen pensar en la violencia de mediados de este siglo), que el partido liberal ganó-y con bastante mal humor, demostrado por los centenares de decretos de prisión y exilio contra conservadores (grandes y pequeños) a partir de 1861. Además, los prohombres liberales del nuevo Estado Soberano de Santander no eran nada amigos de la autonomía local, que habría permitido reductos locales del conservatismo a lo largo del estado. Pero la experiencia de 1857 a 1860 influyó profundamente a los líderes liberales, como bien lo ha analizado David Johnson; ahora rechazaron el sufragio universal, el impuesto único directo, y la doctrina ultracentralizante que había suprimido los cabildos municipales. ${ }^{52}$ Se dieron cuenta de que un régimen estatal estable tenía que apelar a las élites locales, más que al esperado fervor ideológico del pueblo.

A mediados de los años 60, cuando las medidas represivas contra el conservatismo fueron levantadas, los dirigentes locales de San Gil y otros pueblos podían volver a una vaga semblanza del juego pre-1850: una búsqueda permanente de ventajas frente a pueblos vecinos y contra el gobierno del Estado mismo, pero ahora sin el temor penetrante de que el orden social local podría estar ligado al tema, como ocurrió durante la década de los años 50. San Gil no había perdido su talento en aquellas pugnas: una victoria importante de San Gil contra Barichara en 1869, sobre la sede departamental (subregional), dejó atónitos a los fieles liberales de Barichara. ${ }^{53}$ El hecho de

51 Entre ellos, el deseo de intimidar al general Mosquera, quien desde el Cauca se preparaba a declarar la guerra al gobierno central; el deseo de alejar de Bogotá al general Herrán, cuya candidatura presidencial no era del agrado del saliente Ospina; y quizás el sincero deseo de rescatar al conservatismo del nororicnte, que Ospina había sacrificado a la dominación radical en 1857 como un "mal necesario," para desacreditar al liberalismo en su "vitrina" principal. Para las guerras de 1859 a 1861, véase Stoller, Liberalism and Conflict, pp. 318-328.

52 Johnson, Santander siglo $X J X$, pp. 201-283; para el rechazo del sufragio universal, véase especialmente Adriano Pácz, La Constitución del estado Soberano de Santander puesta al alcance del pueblo, Socorro, t. I., Céspedes, 1865, y el "Informe del Presidente de Santander a la Asamblea..." 1866, Socorro, r. 1, Céspedes, 1866; El Norte, Socorro, 30 agosto, 9 y 13 septiembre 1862.

53 Como lo recordó un anónimo escritor de Barichara en El Republicano, Socorro, 3 junio 1875. 
que los liberales santandereanos más identificados con el radicalismo de 1857-1860 ya estaban en Bogotá, presidiendo el "Olimpo Radical", hizo que los oponentes de aquellas ideas en Santander apoyaran a un gobierno estatal fuerte (aunque también liberal), como contrapeso. La elección del declarado radical Victoriano de Diego Paredes a la presidencia del Estado en 1866 puso en cuestión esta estrategia, pero la rápida reacción de las élites liberales del Estado contra Paredes cuando propuso reformar la ley laboral a favor de los jornaleros, presionando su renuncia, ratificó su relativa viabilidad. ${ }^{54}$ Pero no se pudo volver completamente al juego original, porque la división partidista inevitablemente influyó en la dinámica de los conflictos jurisdiccionales, y más profundamente, porque la élite sangileña había sido traumatizada por su encuentro con el radicalismo liberal. Martínez, su vocero permanente, no encontró mucho qué escoger entre la "secta demoledora, impía, desleal," y "disolvente" del antiguo golgotismo, y la alarmante composición social del mosquerismo-así que no pudo decidir entre un regreso al centralismo, con su riesgo de ser controlado por una u otra facción liberal, y un renovado federalismo de estados más pequeños, que le diera al conservatismo (social y partidista) sangüeño algunas garantías de hegemonía local con un buen trazado de linderos. ${ }^{55}$ El rompecabezas no tuvo solución sino en 1885, con el movimiento conservador-nuñista y la promulgación de un reordenamiento abiertamente centralista.

\section{A MODO DE CONCLUSIÓN}

La historia que acabo de bosquejar, en forma algo intermitente y hasta arbitraria, no niega que los socorranos del siglo XIX. hubieran sido instrumentalistas en sus perspectivas sobre la organización estatal: pensaban primero en los beneficios que deseaban disfrutar (en cuanto a privilegios y atributos burocrá-tíco-fiscales en la primera época, y en la preservación del orden social en la segunda, en términos muy bruscos), y después (al menos analíticamente) en el tipo de organización estatal que mejor garantizaría aquellos beneficios. De haber obrado de otro modo, las gentes aquí tratadas serían tan exóticas como para rayar en la inverosimilitud—precisamente el tipo de gentes que hemos encontrado, en forma individualizada, en muchas biografías "heróicas" de tipo tradicional.

54 Johnson, Santander siglo XIX, 204-205, y los impresos coleccionados en la Biblioteca Nacional de Colombia, Fondo Pineda, 982 (antigua numeración).

55 Véase la correspondencia de Martínez con Herrán, especialmente durante la crisis política de 1867: cartas del 10 y 31 de mayo y 15 de julio de 1867, y 24 de noviembre de 1868, en Archivo del General Pedro A/cántara Herrán. Academia Colombiana de Historia. 
Espero haber abierto un tema de vigencia historiográfica para la Colombia del Siglo XIX, bajo dos aspectos. Primero, como ingrediente importante de la historia regional: una historia del Socorro que hace caso omiso de los conflictos jurisdiccionales no puede explicar satisfactoriamente elementos importantes de identidad política, que vinieron a conformar el mapa partidista de Santander tan bien comentado por Eduardo Caballero Calderón y otros escritores. ${ }^{56}$ Obviamente las pugnas lugareñas no explican más que una parte de la evolución del mapa partidista, pero da muestras de ser una parte imprescindible, especialmente por su vigencia durante la época clave de formación y arraigo de los partidos políticos a mediados del siglo pasado." Que estas pugnas tengan una importancia semejante para otras regiones del país es algo que requiere una nueva ronda de investigación. Como tema de investigación tiene ciertas ventajas, pues su aspecto institucional lo hace relativamente accesible, en comparación con temas de mentalités, o estudios económicos de larga duración. Segundo, como tema fundado en los nexos entre los varios niveles del Estado, constituye un aspecto importante en la eterna cuestión "de cómo se ha formado la nación colombiana": ¿Esta realmente existió en el siglo pasado? ¿Qué significado tenía la pertenencia a una entitad política superior? ¿Bajo qué condiciones los colombianos/ granadinos de determinada localidad buscaban alianzas discursivas o concretas con sus semejantes más allá de las estrechas fronteras fijadas por la geografía y el comercio cotidiano? La ironía más interesante de todas, sería encontrar que los centenares de decisiones instrumentales de localidades y de facciones locales sumaran una panorámica de la política nacional coherente, cuya misma coherencia (fruto de la lucha entre dos partidos polarizados y más o menos equilibrados) retornara sobre las localidades en las varias y nefastas formas ampliamente estudiadas para el presente siglo.

56 Eduardo Caballero Calderón, Cartas colombianas, Bogotá, Ed. Kelly, 1949, pp. 81-161, especialmente p. 139.

57 Palabras del gobernador Ramón Mateus en 1852, sobre disputas de linderos entre Oiba y Guadalupe, Confines y Guapotá, y Robada y Palmar: "es sensible que los espedientes que se crean para efectuar esta reforma [de linderos], sean otros tantos feudos de odio que han de pasar a la jeneración venidera." Informe del Gobernador del Socorro a la Camara Provincial, Gaceta Oficial, 24 diciembre 1852. 